\title{
Loss of heterozygosity on chromosome 5 in Iranian esophageal cancer patients
}

\author{
F. Attaran-Bandarabadi ${ }^{1}$, A.A. Ziaee ${ }^{1}$, M. Yazdanbod ${ }^{2}$, M. Shahpanah ${ }^{3}$, \\ A. Setayeshgar ${ }^{4}$ and M. Nassiri ${ }^{4}$ \\ ${ }^{1}$ Institute of Biochemistry and Biophysics, University of Tehran, Tehran, Iran \\ ${ }^{2}$ Department of Surgery, Madaen Hospital, Tehran, Iran \\ ${ }^{3}$ Delivery Room, Bank Melli Iran Hospital, Tehran, Iran \\ ${ }^{4}$ Pathology Department, Madaen Hospital, Tehran, Iran \\ Correspondence author: A.A. Ziaee \\ E-mail: aaziaee@ibb.ut.ac.ir
}

Genet. Mol. Res. 10 (4): 2316-2325 (2011)

Received November 23, 2010

Accepted May 19, 2011

Published October 5, 2011

DOI http://dx.doi.org/10.4238/2011.October.5.2

\begin{abstract}
There is a high incidence of esophageal squamous cell carcinoma (ESCC) in Iran. Non-functionality of some tumor suppressor genes has been reported in esophageal cancer. Loss of heterozygosity on chromosome 5 has also been reported in esophageal carcinomas. We assessed loss of heterozygosity along a region of the long arm of chromosome 5 (5q), from 5q23.1 to 5q23.2, by PCR amplifying DNA fragments of tumor tissues from patients with ESCC and their corresponding normal samples. The PCR products were electrophoresed on $6 \%$ non-denaturing polyacrylamide gels, and band intensity was shown by silver staining. Of 40 patients with ESCC, 27, 25 and 36\% of informative cases showed allelic losses at microsatellite markers D5S1384, D5S1478 and D5S1505, respectively. Two of the 40 patients studied had microsatellite instability at marker D5S1384. Based on the fact that loss of heterozygosity with more than $22 \%$ incidence for a specific marker cannot be regarded as a random event, we add support to previous reports concerning the presence of tumor suppressor genes in this chromosome region and that they affect esophageal cancer
\end{abstract}


development. According to the data in NCBI UniSTS, the PCR product size of human DNA with primers of the D5S1505 marker ranges from 243 to $275 \mathrm{bp}$, containing about 20 repeats of the TAGA tetranucleotide, while the amplicon size of one allele of one of our cases was $207 \mathrm{bp}$, with about 10 repeats of the TAGA tetranucleotide, which would be the shortest sequence reported so far.

Key words: Esophagus cancer; Esophageal squamous cell carcinoma; Loss of heterozygosity; Microsatellite instability; Chromosome 5; Iran

\section{INTRODUCTION}

Esophagus cancer is the sixth most common cancer worldwide (Parkin et al., 2005). There are two pathological types of esophageal cancer: esophageal squamous cell carcinoma (ESCC) and esophageal adenocarcinoma (EAC). ESSCs constitute $98 \%$ of esophageal neoplasias (Mathew et al., 2001), but EAC is currently increasing in the world (Wei and Shaheen, 2003; Haghdoost et al., 2008). A high incidence of ESCC has been reported in northern Iran. Esophagus cancer is characterized by a poor prognosis with a post-operative survival of 26 to $54 \%$ (Hosch et al., 2003). Seventy-five percent of patients die within one year after diagnosis (Hiyama et al., 2007), while five-year survival is less than 5\%. The risk of developing esophageal cancer increases with age, and the highest incidence has been reported to be at the age of 50 to 70 years (Kollarova et al., 2007). Most patients diagnosed with esophageal cancer live in the so-called Asian esophageal cancer belt, including parts of northern Iran (Lam et al., 2000). In general, unlike high-risk populations, in which incidence rates for ESCC among males have been reported to be the same as those of females, in low-risk populations the majority of cases are males (Franco and Rohan, 2002). Epidemiological studies indicate that esophageal cancer is associated with the consumption of alcohol, tobacco, pickled vegetables, and hot drinks. These factors render the esophageal mucosa more susceptible to injuries caused by carcinogenic contaminations such as mycotoxins, nitrosyl compounds and possibly human papilloma and Epstain-Barr viruses (Lam, 2000). In addition to environmental factors, genetic factors have been suggested to play important roles in the development of esophageal cancer (Hiyama et al., 2007).

The activation of oncogenes and inactivation of tumor suppressor genes (TSGs) play roles in the etiology of cancer. Loss of heterozygosity $(\mathrm{LOH})$ studies have proven to be useful for assessing TSG deletions and also for mapping candidate regions harboring potential TSGs (Zheng et al., 2005).

Microsatellite sequences are tandem repeats of short sequences that are scattered throughout the genome. Alterations of these repeats could serve as markers of a mutator phenotype in cancer following the approach of LOH analysis (Loeb, 1994). LOH has been detected at several chromosomal locations, such as chromosome 2q, 3p, 4p, 4q, 5q, 6q, 8p, 9p, 9q, 11p, 13q, 14q, 15q, and 17p in esophageal cancer (Hu et al., 2000)

$\mathrm{LOH}$ at loci of the tumor suppressor genes APC and $\mathrm{MCC}$ and the mismatch repair gene, MSH3, on chromosome 5q have been reported in esophageal carcinomas (Bodmer et al., 1987; Boynton et al., 1992). Since the observed allelic deletions were not limited to APC/ MCC loci (5q21), some other relevant genes have been suggested to be located in this region of chromosome 5 (Boynton et al., 1992). 
We used three microsatellite markers that cover chromosome 5 from $5 \mathrm{q} 23.1$ to $5 \mathrm{q} 23.2$ to analyze both $\mathrm{LOH}$ and microsatellite instability (MSI) of this chromosomal region in 40 Iranian ESCC patients.

\section{MATERIAL AND METHODS}

\section{Tumor tissues and blood samples}

Tumor tissues and peripheral blood samples were collected from 40 Iranian patients with ESCC. The tissue specimens that were examined by a pathologist were stored at $-70^{\circ} \mathrm{C}$ until the time of use. Pathological parameters of tumors are described in Table 1. Blood samples were mixed with EDTA as an anticoagulant and stored at $-20^{\circ} \mathrm{C}$. DNA derived from blood samples was used as normal DNA.

\begin{tabular}{|c|c|c|c|c|c|c|c|c|c|}
\hline $\begin{array}{l}\text { Case } \\
\text { No. }\end{array}$ & Gender & $\begin{array}{c}\text { Age } \\
\text { (years) }\end{array}$ & Differentiation & LNM & $\begin{array}{l}\text { Case } \\
\text { No. }\end{array}$ & Gender & $\begin{array}{c}\text { Age } \\
\text { (years) }\end{array}$ & Differentiation & LNM \\
\hline 1 & M & 55 & $x$ & + & 21 & $\mathrm{~F}$ & 60 & Moderately differentiated & + \\
\hline 2 & M & 73 & Poorly to moderately differentiated & - & 22 & M & 65 & Well differentiated & + \\
\hline 3 & M & 55 & Well differentiated & + & 23 & $\mathrm{~F}$ & 55 & Moderately differentiated & + \\
\hline 4 & M & 45 & Poorly differentiated & + & 24 & $\mathrm{~F}$ & 66 & Moderately differentiated & + \\
\hline 5 & $\mathrm{~F}$ & 40 & Moderately differentiated & + & 25 & M & 70 & Moderately differentiated & + \\
\hline 6 & $\mathrm{~F}$ & 51 & Well differentiated & + & 26 & M & 67 & Well differentiated & + \\
\hline 7 & M & 81 & Moderately differentiated & + & 27 & M & 68 & $x$ & $x$ \\
\hline 8 & M & 65 & Moderately differentiated & - & 28 & $\mathrm{~F}$ & 56 & Moderately to well differentiated & + \\
\hline 9 & $\mathrm{~F}$ & 55 & Moderately differentiated & - & 29 & M & 58 & Well differentiated & - \\
\hline 10 & M & 53 & $\times$ & - & 30 & M & 70 & Moderately differentiated & - \\
\hline 11 & M & 60 & Well differentiated & + & 31 & $\mathrm{~F}$ & 52 & Well differentiated & - \\
\hline 12 & M & 67 & Moderately differentiated & + & 32 & M & 81 & Poorly differentiated & - \\
\hline 13 & M & 39 & Undifferentiated & - & 33 & $\mathrm{~F}$ & 72 & $x$ & $x$ \\
\hline 14 & M & 60 & Moderately differentiated & + & 34 & M & 35 & Moderately to poorly differentiated & - \\
\hline 15 & $\mathrm{~F}$ & 70 & Well differentiated & + & 35 & $\mathrm{~F}$ & 70 & Well differentiated & - \\
\hline 16 & $\mathrm{~F}$ & 54 & $\times$ & $x$ & 36 & $\mathrm{~F}$ & 55 & $\times$ & $\times$ \\
\hline 17 & $\mathrm{~F}$ & 40 & Well differentiated & - & 37 & M & 48 & Well differentiated & + \\
\hline 18 & M & 70 & Well differentiated & - & 38 & $\mathrm{~F}$ & 58 & Moderately differentiated & + \\
\hline 19 & M & 55 & $\times$ & $x$ & 39 & M & 54 & Moderately differentiated & + \\
\hline 20 & M & 60 & Well differentiated & + & 40 & $\mathrm{~F}$ & 42 & Moderately differentiated & - \\
\hline
\end{tabular}

$x=$ data not available; $\mathrm{LNM}=$ lymph node metastasis.

\section{DNA extraction}

Tissue specimens were dissected, and adipose and connective tissues were removed; the specimens were then suspended in buffer containing $0.15 \mathrm{mM} \mathrm{NaCl}, 10 \mathrm{mM}$ EDTA, and $10 \mathrm{mM}$ Tris- $\mathrm{HCl}, \mathrm{pH} 7.5$, and lysed following the addition of $50-100 \mu \mathrm{g} / \mathrm{mL}$ proteinase $\mathrm{K}$ and SDS (final concentration of $0.5 \%$ ). The lysate was incubated at $56^{\circ} \mathrm{C}$ for $2 \mathrm{~h}$ and then mixed with an equal volume of phenol. After gentle mixing and centrifugation at 14,000 rpm for 5 min, the supernatant was mixed with an equal volume of chloroform/isoamyl alcohol (24:1). The mixture was centrifuged at 14,000 rpm for $5 \mathrm{~min}$, and the supernatant was diluted with 2.2 volumes of absolute ethanol. The precipitated DNA was washed with $70 \%$ ethanol, dissolved in 50-100 $\mu \mathrm{L}$ TE $(10 \mathrm{mM}$ Tris, $1 \mathrm{mM}$ EDTA, $\mathrm{pH} 7.5)$, and then stored at $-20^{\circ} \mathrm{C}$ (Lane et al., 1995). DNA was extracted from blood using the procedure of Barlett and Stirling (2003) with 
slight modifications. A volume of $3 \mathrm{~mL}$ frozen blood was thawed at $37^{\circ} \mathrm{C}$ and mixed with 12 $\mathrm{mL}$ buffer A (containing $320 \mathrm{mM}$ sucrose, $0.01 \mathrm{M}$ Tris- $\mathrm{HCl}, \mathrm{pH} 7.4,5 \mathrm{mM} \mathrm{MgCl}, 1 \%$ Triton $\mathrm{X}-100$ ) and centrifuged at $3000 \mathrm{~g}$ for $15 \mathrm{~min}$. The pellet was suspended in buffer B (containing 0.4 M Tris-HCl, $0.06 \mathrm{M}$ EDTA, $150 \mathrm{mM} \mathrm{NaCl}, 1 \% \mathrm{SDS}, \mathrm{pH} 8.0$ ) and $250 \mu \mathrm{L} 5 \mathrm{M}$ sodium perchlorate. The mixture was incubated in a $65^{\circ} \mathrm{C}$ water bath for $20 \mathrm{~min}$; afterwards, $2 \mathrm{~mL}$ icecold chloroform was added. After centrifugation at $2400 \mathrm{~g}$ for $2 \mathrm{~min}$, DNA was precipitated with 2-3 mL ice-cold ethanol. The precipitated DNA was washed with $70 \%$ ethanol, dissolved in 50-100 $\mu \mathrm{L} \mathrm{TE}$ and kept at $-20^{\circ} \mathrm{C}$.

\section{PCR and microsatellite analysis}

The LOH status of 40 ESCC patients was analyzed using polymerase chain reaction (PCR) amplification of three microsatellite repeats on chromosome 5 from 5q23.1 to 5q23.2. Characteristics of the microsatellite markers are shown in Table 2, according to data on the NCBI web-site (NCBI UniSTS, Map Viewer; www.ncbi.nlm.nih.gov/mapview/genome/sts). To amplify the target DNA sequences from tumor tissues and blood samples, we used the PCR in $50 \mu \mathrm{L} \mathrm{PCR}$ mixtures containing $12.5 \mathrm{ng}$ DNA, $5 \mu \mathrm{L}$ 10X PCR buffer, $3.75 \mathrm{mM} \mathrm{MgCl}, 0.31 \mathrm{mM}$ dNTPs, $1.25 \mu \mathrm{L}$ formamide, $2.5 \mathrm{U}$ Taq DNA polymerase, and $0.62 \mu \mathrm{M}$ of each primer. The cycling conditions were as follows: initial denaturation at $94^{\circ} \mathrm{C}$ for $5 \mathrm{~min}$, followed by 35 cycles at $94^{\circ} \mathrm{C}$ for $30 \mathrm{~s}, 60-63^{\circ} \mathrm{C}$ for $30 \mathrm{~s}, 72^{\circ} \mathrm{C}$ for $30 \mathrm{~s}$, and a final extension at $72^{\circ} \mathrm{C}$ for $5 \mathrm{~min}$. The PCR products were then mixed with $5 \mu \mathrm{L}$ loading buffer (98\% formamide, $20 \mathrm{mM}$ EDTA, $0.05 \%$ bromophenol blue, and $0.05 \%$ xylene cyanol) and after denaturing at $95^{\circ} \mathrm{C}$ for $10 \mathrm{~min}$, electrophoresed on a $6 \%$ non-denaturing polyacrylamide gel at $400 \mathrm{~V}$ for $1-2 \mathrm{~h}$ (Garcia, et al. 2003). Tumor and normal samples from the same patient were loaded side by side and the bands were visualized with a silver-staining method (Blum et al., 1987; Bassam and Caetano-Anollés, 1993). If one of the bands vanished completely or showed a diminution in intensity in the tumor DNA compared with the corresponding normal DNA, the tumor would be considered to have undergone loss of heterozygosity at the aforementioned loci. If some extra band(s) appeared in a tumor DNA in comparison to the corresponding normal sample, it would be interpreted as microsatellite instability.

Table 2. Characteristics of microsatellite markers.
\begin{tabular}{llccllll}
\hline Marker & Position $(\mathrm{Mb})$ & Site & $\mathrm{Ta}\left({ }^{\circ} \mathrm{C}\right)$ & Size $(\mathrm{bp})$ & F-primer & R-primer \\
\hline D5S1384 & $118,857,860-118,858,038$ & $5 \mathrm{q} 23.1$ & 61 & 179 & CTAAACAGAAAAGAGCTAAGCCTA & TACCTACCTATATGCTCCCAATC \\
D5S1478 & $118,938,794-118,939,003$ & $5 \mathrm{q} 23.1$ & 60 & $194-221$ & TGGTGTTTCCAGAATCACT & TTGTGCTACAGGGGAATCAT \\
D5S1505 & $119,129,545-119,129,801$ & $5 \mathrm{q} 23.2$ & 63 & $243-275$ & TAAGTGCCAGAGTCTCCCAC & TAAGGCATGTCTCGGAGCTA \\
\hline
\end{tabular}

$\mathrm{Mb}=$ mega-base pairs; $\mathrm{Ta}=$ annealing temperature.

\section{Statistical analysis}

The Fisher exact test was applied to determine the association between some pathological parameters and $\mathrm{LOH}$ at a specific marker.

\section{Cloning procedure}

PCR fragments of each allele for the D5S1505 marker from patient number 11, whose 
one allele showed the shortest length, were ligated into (SmaI) linearized pBluescript II KS (+/-) (Sambrook et al., 1989). DH5 $\alpha$ competent cells were transformed with plasmids (Perbal, 1988); afterwards, recombinants were identified via blue-white screening. Plasmids were spin-column prepared; the sequences were then determined by Geneservice, Ltd. (UK).

\section{RESULTS}

Forty Iranian ESCC patients between the ages of 35 to 81 years were studied. Twenty-four patients $(60 \%)$ were males and sixteen patients $(40 \%)$ were females. Representative electrophoresis is exhibited in Figure 1. Six of $22(27 \%)$ heterozygous cases showed LOH at marker D5S1384. Four of $16(25 \%)$ and 8 of $22(36 \%)$ heterozygous cases showed LOH at markers D5S1478 and D5S1505, respectively (Table 3). There is no escaping the fact that the loss of one allele among the homozygous cases is not improbable; however, they are considered to be non-informative cases. The $\mathrm{LOH}$ frequencies of markers in tumors with different pathological parameters are shown in Table 1. The Fisher exact test showed no association between $\mathrm{LOH}$ and differentiation or metastasis stages of tumors $(\mathrm{P}>0.05)$. Two cases showed MSI with marker D5S1384. We also found one patient (number 11) in which the PCR product size of one allele with primers of marker D5S1505 was $207 \mathrm{bp}$, containing about 10 TAGA repeats, which could be regarded as the shortest sequence reported so far (Figures 2-4).
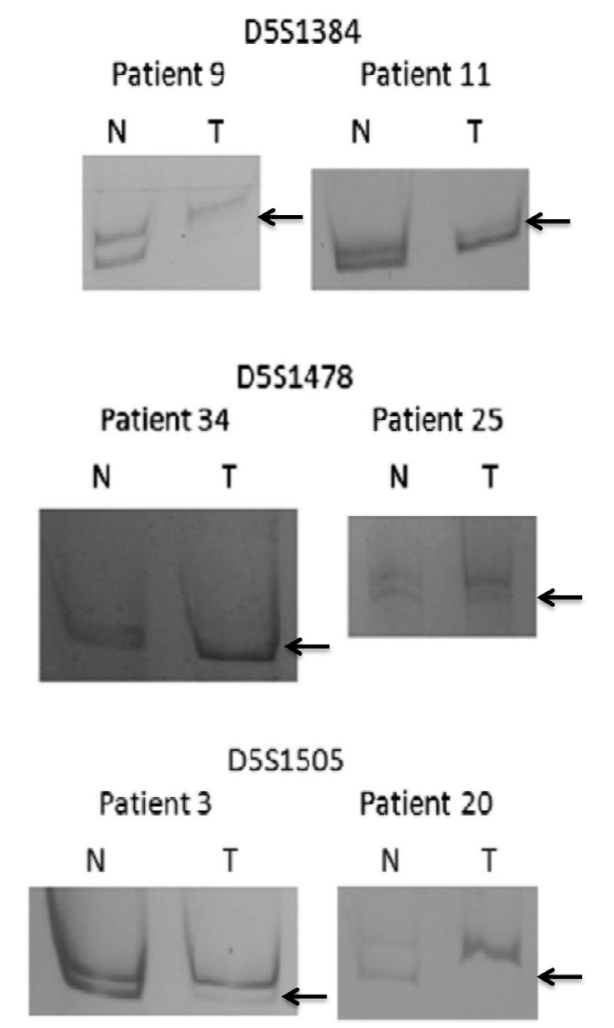

Figure 1. Some samples with loss of heterozygosity. $\mathrm{N}=$ normal; $\mathrm{T}=$ tumor. 
Table 3. Results of loss of heterozygosity analysis.

\begin{tabular}{|c|c|c|c|c|c|c|c|}
\hline Sample & D5S1384 & D5S1478 & D5S1505 & Sample & D5S1384 & D5S1478 & D5S1505 \\
\hline 1 & o & $x$ & $\bullet$ & 21 & $x$ & $x$ & $\bullet$ \\
\hline 2 & $\times$ & $x$ & $x$ & 22 & $\circ$ & $\times$ & $x$ \\
\hline 3 & o & $\bullet$ & - & 23 & ○ & $\times$ & $x$ \\
\hline 4 & $x$ & $x$ & $x$ & 24 & $\circ$ & $\times$ & $x$ \\
\hline 5 & $\bullet$ & $x$ & ○ & 25 & $\bullet$ & $\bullet$ & ○ \\
\hline 6 & 0 & $\circ$ & $x$ & 26 & $x$ & $\bullet$ & $\bullet$ \\
\hline 7 & $\bullet$ & $x$ & 0 & 27 & 0 & $\times$ & 0 \\
\hline 8 & $x$ & $\circ$ & $\times$ & 28 & $x$ & $\circ$ & $x$ \\
\hline 9 & • & $x$ & $\bullet$ & 29 & $x$ & $\circ$ & $\circ$ \\
\hline 10 & $\times$ & $\circ$ & $\circ$ & 30 & $\circ$ & $\circ$ & $\circ$ \\
\hline 11 & $\bullet$ & $x$ & 0 & 31 & MSI & $x$ & $x$ \\
\hline 12 & $x$ & 0 & $x$ & 32 & $x$ & $x$ & $\bullet$ \\
\hline 13 & 0 & $x$ & o & 33 & ○ & $x$ & $x$ \\
\hline 14 & $\times$ & $\circ$ & $\circ$ & 34 & $x$ & $\bullet$ & $x$ \\
\hline 15 & $x$ & $x$ & ○ & 35 & $x$ & $\times$ & $x$ \\
\hline 16 & $\bullet$ & $\circ$ & - & 36 & $x$ & $\times$ & $x$ \\
\hline 17 & $\circ$ & $\circ$ & $\circ$ & 37 & $x$ & $\circ$ & $x$ \\
\hline 18 & $\circ$ & $x$ & $x$ & 38 & $\circ$ & $\times$ & $\circ$ \\
\hline 19 & ० & $x$ & $x$ & 39 & $\circ$ & $\circ$ & $\circ$ \\
\hline 20 & MSI & $x$ & $\bullet$ & 40 & $\circ$ & $\times$ & $x$ \\
\hline
\end{tabular}

- = loss of heterozygosity; $\circ=$ heterozygous; $\times$ = homozygous (non-informative); MSI = microsatellite instability.

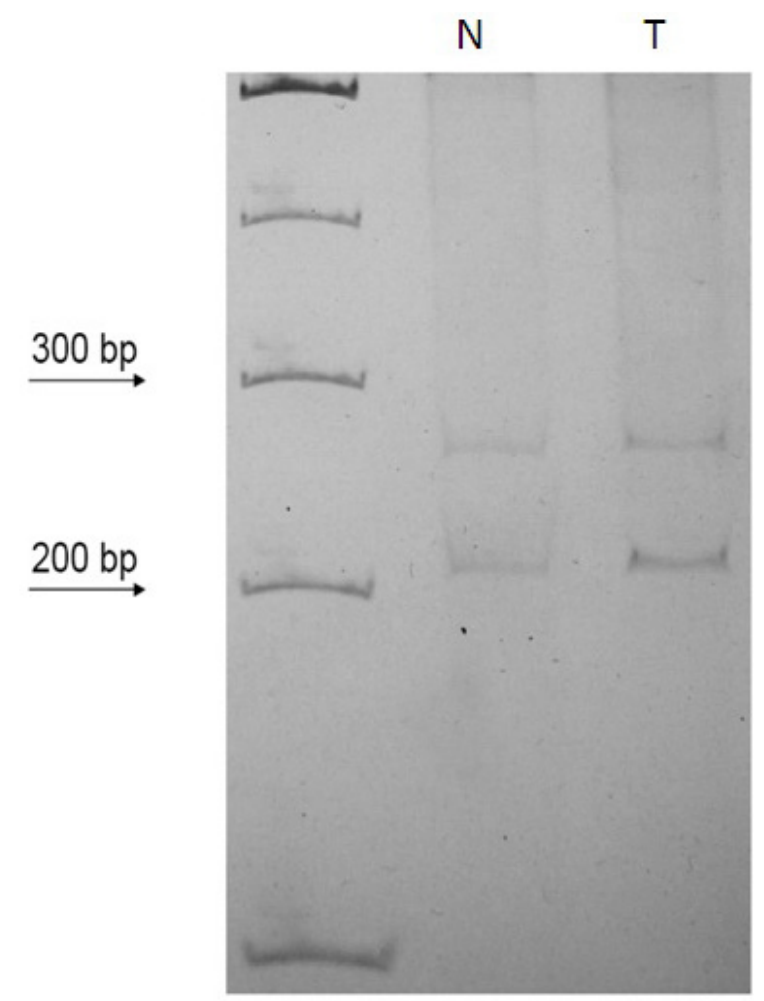

Figure 2. The PCR product size of sample 11 with primers of marker D5S1505. $\mathrm{N}=$ normal; $\mathrm{T}=$ tumor. 
NNNNNNNNNNNNNGNNGCGGCCGCTCTAGAACTAGTGGATCCCCCTAAGTGCCAGA GTCTCCCACTACTGATGATCAATGGTGTCAACAAAGTAATGTAAAGACAGACAGAGA GATTAGATAGATAGATAGATAGATAGATAGATAGATAGATAAATAGATATAGATAG ATAGATAGATAGATAGATAGATAGATAGATAAATAGATAAATGAGAAAAAGAGATA TCAGCAGAAAACAATATGTATCCACTGAGACGCTCTCCACTCACTTTACTGGGTAGC TCCGAGACATGCCTTAGGGCTGCAGGAATTCGATATCAAGCTTATCGATACCGTCGA CCTCGAGGGGGGGCCCGGTACCAGCTTTTGTTCCCTTTAGTGAGGGTTAATTTCGAGC TTGGCGTAATCATGGTCATAGCTGTTTCCTGTGTGAAATTGTTATCCGCTCACAATTC CACACAACATACGAGCCGGAAGCATAAAGTGTAAAGCCTGGGGTGCCTAATGAGTG AGCTAACTCACATTAATTGCGTTGCGCTCACTGCCCGCTTTCCAGTCGGGAAACCTGT CGTGCCAGCTGCATTAATGAATCGGCCAACGCGCGGGGAGAGGCGGTTTGCGTATTG GGCGCTCTTCCGCTTCCTCGCTCACTGACTCGCTGCGCTCGGTCGTTCGGCTGCGGCG AGCGGTATCAGCTCACTCAAAGGCGGTAATACGGTTATCCACAGAATCAGGGGATA ACGCAGGAAAGAACATGTGAGCAAAAGGCCAGCAAAAGGCCAGGAACCGTAAAAA GGCCGCGTTGCTGGCGTTTTTCCATAGGCTCCGCCCCCCTGACGAGCATCACAAAAA TCGACGCTCAAGTCAGAGGTGGCGAAACCCGACAGGACTATAAAGATACCAGGCGT TTCCCCCTGGAAGCTCCCTCGTGCGCTCTCCTGTTCCGACCCTGCCGCTTACCGGATA CCTGTCCGCCTTTCTCCCTTCGGGAAGCGTGNNCTTTCTCATAGCTCACGCTGTANGN NNCTCAGTTCGGNNGN

Figure 3. The sequence of one allele amplicon ( $253 \mathrm{bp}$ ) with primers of marker D5S1505 from normal sample of the patient number 11 .

NNNNNNNNNNCNNNGGNNNGCGGCCGCTCTAGAACTAGTGGATCCCCCTAAGTGCC
AGAGTCTCCCACTACTGATGATCAATGGTGTCAACAAAGTAATGTAAAGACAGACAG
AGAGATTAGATAGATAGATAGATAGATAGATAGATAGATAGATAAATAGATAAATG
AGAAAAAGAGATATCAGCAGAAAACAATATGTATCCACTGAGACGCTCTCCACTCA
CTTTACTGGGTAGCTCCGAGACATGCCTTAGGGCTGCAGGAATTCGATATCAAGCTT
ATCGATACCGTCGACCTCGAGGGGGGGCCCGGTACCAGCTTTTGTTCCCTTTAGTGA
GGGTTAATTTCGAGCTTGGCGTAATCATGGTCATAGCTGTTTCCTGTGTGAAATTGTT
ATCCGCTCACAATTCCACACAACATACGAGCCGGAAGCATAAAGTGTAAAGCCTGG
GGTGCCTAATGAGTGAGCTAACTCACATTAATTGCGTTGCGCTCACTGCCCGCTTTCC
AGTCGGGAAACCTGTCGTGCCAGCTGCATTAATGAATCGGCCAACGCGCGGGGAGA
GGCGGTTTGCGTATTGGGCGCTCTTCCGCTTCCTCGCTCACTGACTCGCTGCGCTCGG
TCGTTCGGCTGCGGCGAGCGGTATCAGCTCACTCAAAGGCGGTAATACGGTTATCCA
CAGAATCAGGGGATAACGCAGGAAAGAACATGTGAGCAAAAGGCCAGCAAAAGGC
CAGGAACCGTAAAAAGGCCGCGTTGCTGGCGTTTTCCATAGGCTCCGCCCCCCTGA
CGAGCATCACAAAAATCGACGCTCAAGTCAGAGGTGGCGAAACCCGACAGGACTAT
AAAGATACCAGGCGTTTCCCCTGGAAGCTCCCTCGTGCGCTCTCCTGTTCCGACCCT
GCCGCTTACCGGATACCTGTCCGCCTTTCTCCCTTCGGGAAGCGTGGCGCTTTCTCAT
AGCTCACGCTGTNNNTATCTCAGTTCGGTGTAGGTCGNTCGCTCCAAGCTGGGCTGT
GTGCACGAACCCCCCGTTCAGCCCGACCGCTGCNNNN

Figure 4. The sequence of the other allele amplicon (207 bp) with primers of marker D5S1505 from normal sample of the patient number 11 . 


\section{DISCUSSION}

Generally, it has been accepted that if one of the alleles of a TSG is mutated and the other is deleted, the gene will fail to function (Peralta et al., 1998). Thus, LOH at TSG loci would have an influence on tumorigenesis. Allelic losses on the small arm of chromosome 5 (5p) have been reported in hepatocyte carcinoma, lung cancer and cervix carcinoma (Dolan et al., 2000). Similarly, losses on the $5 \mathrm{q}$ arm were observed in many digestive tract malignancies such as of the colon, stomach and esophagus (Kanazawa et al., 2002). The highest incidence of LOH on chromosome $5 \mathrm{q}$ (5q35-ter) was detected in well-differentiated gastric adenocarcinoma (Sano et al., 1991). Seventy-seven percent of patients with ESCC, who showed high $\mathrm{LOH}$ frequencies, were detected in regions harboring the TSGs APC, MCC or both (Lee et al., 1990). Furthermore, allelic deletion at the tumor suppressor gene irf-1 locus (5q31.1) was observed in $44 \%$ of esophageal cancer patients (Peralta et al., 1998). Since deletions often involve several kilo base pairs and are not limited to these genes, some unknown TSG(s) may be present on chromosome 5 whose deletion is important in tumor development.

We carried out a set of experiments using three microsatellite markers to scan for deletions along the regions probably harboring TSG(s) on 5 q. In our study 27,25 and $36 \%$ of 40 Iranian patients with esophageal cancer showed LOH at the D5S1384, D5S1478 and D5S1505 markers, respectively. It was suggested that LOH with less than $22 \%$ incidence for a marker could be regarded as a non-specific event (Cai et al., 2007). Thus, the deletions we observed were not random occurrences and a TSG(s) is/are probably located near the region studied. Deletions at markers D5S1384 and D5S1505 may involve the APC/MCC and irf-1 genes, respectively. $\mathrm{LOH}$ at these TSGs may have an impact on cancer development. It is also possible that some unknown TSGs exist in deleted regions. There are 272 kbp between markers D5S1384 and D5S1505 (Li et al., 2004) containing two genes and three pseudogenes, according to data in NCBI (NCBI Map Viewer; http://www.ncbi.nlm. nih.gov/mapview). One of the genes is HSD17B4, which encodes a bifunctional enzyme that is involved in the peroxisomal beta-oxidation pathway for fatty acids. It also acts as a catalyst for the formation of 3-ketoacyl-CoA intermediates from both straight-chain and 2-methyl-branched-chain fatty acids (Moller et al., 1999). Marker D5S1384 is located in the HSD17B4 gene. The other protein-coding gene is FAM170A. There is only evidence at the transcript level about it (uniprot: A1A519). It is not clear whether alterations of these genes are involved in the process of human carcinogenesis.

Two of the 40 patients studied (5\%) showed MSI at marker D5S1384, which is in agreement with previous reports on MSI. It is reported that MSI occurs frequently in Barrett'sassociated EAC, but not in ESCC (Meltzer et al., 1994). Additionally, there is evidence implying an inverse relationship between LOH and MSI in other cancers (Cai et al., 2007).

Allelic losses in the region that we studied were previously observed in $50 \%$ of the esophageal cancer patients studied in China. This may be due to the nutritional and environmental similarities between Iran and China (Li et al., 2004).

Our statistical analysis showed no association between the differentiation status of tumors and deletions. This result may suggest that $\mathrm{LOH}$ in the chromosomal region studied is an initial event leading to cancer development.

The PCR product size of human DNA with primers of marker D5S1505 is expected to be from 243 to $275 \mathrm{bp}$ according to the NCBI UniSTS database. So far, the length of less than 
$243 \mathrm{bp}$ was not reported for the human genome concerning the marker D5S1505. In one of our samples (number 11), the PCR product sizes of the corresponding normal and tumor DNA with primers of marker D5S1505 were 253 and $207 \mathrm{bp}$, containing about 20 and 10 repeats of a TAGA tetranucleotide, respectively. This may imply that some of the repeated units were lost, probably due to genomic instability, which makes normal cells susceptible to carcinogenesis.

\section{ACKNOWLEDGMENTS}

We wish to thank Dr. Parisa Mousavi-Shafaei, Dr. Mohammad Shafiei and Dr. Fatemeh Davoodi-Dehaghani for their worthwhile guidance.

\section{REFERENCES}

Barlett JMS and Stirling D (2003). Methods in Molecular Biology. 2nd edn. Humana, Totowa.

Bassam BJ and Caetano-Anollés G (1993). Silver staining of DNA in polyacrylamide gels. Appl. Biochem. Biotechnol. 42: 181-188.

Blum H, Beier H and Gross HJ (1987). Improved silver staining of plant proteins, RNA and DNA in polyacrylamide gels. Electrophoresis 8: 93-99.

Bodmer WF, Bailey CJ, Bodmer J, Bussey HJ, et al. (1987). Localization of the gene for familial adenomatous polyposis on chromosome 5. Nature 328: 614-616.

Boynton RF, Blount PL, Yin J, Brown VL, et al. (1992). Loss of heterozygosity involving the APC and MCC genetic loci occurs in the majority of human esophageal cancers. Proc. Natl. Acad. Sci. U. S. A. 89: 3385-3388.

Cai YC, So CK, Nie AY, Song Y, et al. (2007). Characterization of genetic alteration patterns in human esophageal squamous cell carcinoma using selected microsatellite markers spanning multiple loci. Int. J. Oncol. 30: 1059-1067.

Dolan K, Garde J, Walker SJ, Sutton R, et al. (2000). Histological and molecular mapping of adenocarcinoma of the oesophagus and gastroesophageal junction: loss of heterozygosity occurs in histologically normal epithelium in the oesophagus and stomach. Oncol. Rep. 7: 521-528.

Franco EL and Rohan TE (2002). Cancer Precursors Epidemiology, Detection, and Prevention. Springer-Verlag, New York.

Garcia JM, Rodriguez R, Silva J, Munoz C, et al. (2003). Intratumoral heterogeneity in microsatellite alterations in BRCA1 and PTEN regions in sporadic colorectal cancer. Ann. Surg. Oncol. 10: 876-881.

Haghdoost AA, Hosseini H, Chamani G, Zarei MR, et al. (2008). Rising incidence of adenocarcinoma of the esophagus in Kerman, Iran. Arch. Iran. Med. 11: 364-370.

Hiyama T, Yoshihara M, Tanaka S and Chayama K (2007). Genetic polymorphisms and esophageal cancer risk. Int. J. Cancer 121: 1643-1658.

Hosch SB, Stoecklein NH and Izbicki JR (2003). Molecular markers and staging of early esophageal cancer. Langenbecks Arch. Surg. 388: 77-82.

$\mathrm{Hu}$ N, Roth MJ, Polymeropolous M, Tang ZZ, et al. (2000). Identification of novel regions of allelic loss from a genomewide scan of esophageal squamous-cell carcinoma in a high-risk Chinese population. Genes Chromosomes Cancer 27: 217-228.

Kanazawa T, Watanabe T, Kazama S, Tada T, et al. (2002). Poorly differentiated adenocarcinoma and mucinous carcinoma of the colon and rectum show higher rates of loss of heterozygosity and loss of E-cadherin expression due to methylation of promoter region. Int. J. Cancer 102: 225-229.

Kollarova H, Machova L, Horakova D, Janoutova G, et al. (2007). Epidemiology of esophageal cancer - an overview article. Biomed. Pap. Med. Fac. Univ. Palacky Olomouc Czech. Repub. 151: 17-20.

Lam AK (2000). Molecular biology of esophageal squamous cell carcinoma. Crit. Rev. Oncol. Hematol. 33: 71-90.

Lane DP, Midgley CA, Hupp TR, Lu X, et al. (1995). On the regulation of the p53 tumour suppressor, and its role in the cellular response to DNA damage. Philos. Trans. R. Soc. Lond. B Biol. Sci. 347: 83-87.

Lee JH, Kavanagh JJ, Wildrick DM, Wharton JT, et al. (1990). Frequent loss of heterozygosity on chromosomes 6q, 11, and 17 in human ovarian carcinomas. Cancer Res. 50: 2724-2728.

Li XD, Huang XP, Zhao CX, Li QJ, et al. (2004). Identification of a minimal deletion region on chromosome $5 \mathrm{q}$ in Chinese esophageal squamous cell carcinomas. Cancer Lett. 215: 221-228.

Loeb LA (1994). Microsatellite instability: marker of a mutator phenotype in cancer. Cancer Res. 54: 5059-5063.

Genetics and Molecular Research 10 (4): 2316-2325 (2011)

CFUNPEC-RP www.funpecrp.com.br 
Mathew R, Arora S, Mathur M, Chattopadhyay TK, et al. (2001). Esophageal squamous cell carcinomas with DNA replication errors $(\mathrm{RER}+)$ are associated with $\mathrm{p} 16 / \mathrm{pRb}$ loss and wild-type $\mathrm{p} 53$. J. Cancer Res. Clin. Oncol. 127: 603-612.

Meltzer SJ, Yin J, Manin B, Rhyu MG, et al. (1994). Microsatellite instability occurs frequently and in both diploid and aneuploid cell populations of Barrett's-associated esophageal adenocarcinomas. Cancer Res. 54: 3379-3382.

Moller G, Leenders F, van Grunsven EG, Dolez V, et al. (1999). Characterization of the HSD17B4 gene: D-specific multifunctional protein 2/17beta-hydroxysteroid dehydrogenase IV. J. Steroid Biochem. Mol. Biol. 69: 441-446.

Parkin DM, Bray F, Ferlay J and Pisani P (2005). Global cancer statistics, 2002. CA Cancer J. Clin. 55: 74-108.

Peralta RC, Casson AG, Wang RN, Keshavjee S, et al. (1998). Distinct regions of frequent loss of heterozygosity of chromosome 5p and 5q in human esophageal cancer. Int. J. Cancer 78: 600-605.

Perbal BV (1988). A Practical Guide to Molecular Cloning. Wiley Interscience Publication, New York.

Sambrook J, Fritsch EF and Maniatis T (1989). Molecular Cloning, A Laboratory Manual. Cold Spring Harbor, New York.

Sano T, Tsujino T, Yoshida K, Nakayama H, et al. (1991). Frequent loss of heterozygosity on chromosomes 1q, 5q, and $17 \mathrm{p}$ in human gastric carcinomas. Cancer Res. 51: 2926-2931.

Wei JT and Shaheen N (2003). The changing epidemiology of esophageal adenocarcinoma. Semin. Gastrointest. Dis. 14: $112-127$.

Zheng HT, Peng ZH, Li S and He L (2005). Loss of heterozygosity analyzed by single nucleotide polymorphism array in cancer. World J. Gastroenterol. 11: 6740-6744. 